\title{
O Circuito dos Afetos Como Conhecimento dos Corpos Políticos no Desamparo: O Fim do Indivíduo ${ }^{1}$
}

\author{
Zilda M.G.lokoi ${ }^{2}$ \\ ${ }^{1}$ Aula magna do Programa de Pós graduação em Educação e Desenvolvimento Humano da Universidade de \\ Taubaté, ocorrida no dia 07 de março de 2017.

\begin{abstract}
${ }^{2}$ Mestre e doutora em História Social pela Universidade de São Paulo. É professora titular do Departamento de História da Faculdade de Filosofia, Letras e Ciências Humanas da Universidade de São Paulo, na área de História do Brasil Independente, atuando principalmente na linha de pesquisa História das Relações e dos Movimentos Sociais, nos temas da educação, lutas camponesas, políticas públicas, imigração contemporânea, humanidades, direitos e outras legitimidades. É diretora provisória do Diversitas - Núcleo de Estudos das Diversidades, Intolerâncias e Conflitos e coordena o projeto "Fronteiras em Movimento: deslocamentos e outras dimensões do vivido", financiado pelo CNPq
\end{abstract}


Domingo, 12 de Fevereiro de 2017 recebo uma notícia de que o Supremo Tribunal Eleitoral preparara uma manobra para apresentar um conjunto documental produzido pela Lava Jato, para incriminar Lula e Dilma de terem rompido com todos os códigos morais e éticos no exercício de seus mandatos. Os documentos seriam apresentados pela Rede Globo, em partes cortadas aleatoriamente onde aparecessem os nomes dos dois mandatários do poder, de tal modo que, sem possibilidades de qualquer esclarecimentos, a sociedade civil apoiaria o golpe parlamentar já em curso há pelo menos um mês.

Horas depois recebo por WhatsApp o texto de Vladimir Safatle Quando as Ruas Queimam: Manifesto pela Emergência enviado por Sidinei Pires. Nesse material realizo uma reflexão sobre o texto recebido anteriormente, e o Circuito dos Afetos, conforme propus para esse encontro, pois os considero ligados pelos conteúdos teóricos e pelas circunstâncias decorrentes desde os acontecimentos que de 2008 para cá, explicitam como as ruas começaram a queimar e prosseguem em diferentes lugares com intensidade variável desde essa data. Sem possibilidade de correr ou torcer para que o fogo se apague, nosso autor recomenta que nos perguntemos "o que fala o fogo"? O que se diz apenas sob a forma do fogo?

Para ele, a primeira descoberta é a de que o tempo acabou, não há mais como contar o tempo que está nascendo, pois ele produzirá suas narrativas e seus habitantes e contará com números que não conhecemos e terá tensões que não sabíamos existir. Ele será um outro tempo e não haverá mais lugar.

Em 2013, quando no Brasil as ruas continuavam a queimar, elas trouxeram outras possibilidades até então impensadas. Essa singularidade aparece numa pessoa que foi entrevistada por uma jornalista que Ihe pergunta quem é você? A pessoa responde: "anota aí, eu sou ninguém"!

Essa frase é a mais forte de todas as armas políticas, diz Safatle, uma vez que tendo sido controlada a nomeação, controla-se o que irá aparecer e como se construirão os circuitos dos afetos.

Nosso autor afirma que a negatividade ou a negação sempre foi astúcia dos que compreendem que a liberdade passa pela capacidade de destruir o Outro da força da enunciação, dos regimes de visibilidade possíveis. O que é ninguém não pode ser nomeado e nem representado, uma vez que se colocar um vazio que destitui, uma nomeação que quebra os nomes. Contra esse tempo e esse espaço, o poder inventa formas de urgências, de ataques terroristas, de crises econômicas, de violência estatal. O poder passa a exigir solidariedade à situação forjada no medo e no gozo. Paradoxalmente o poder apresenta saídas sem saídas. Os jornalistas afirmam serem as respostas e atitudes do governo, a única hipótese. Não há para eles outra hipótese e, como um mantra dos economistas todos repetem que não há escolhas, que resta apenas uma saída que é impor o conjunto da crise, da forma mais totalitária sobre aqueles que devem pagar por ela sempre.

Esse é o momento que vivemos, onde todos os direitos sociais e as liberdades estão sendo suprimidas e sem possibilidades de "estancar a sangria, não sobre o capital ou os denunciados da lava jato, mas sobre a Constituição e as formas tradicionais de enfrentar a crise, pois estas estão destroçadas e, como líquido podre escorrem e se espalham pelas ruas caminhando para o nada. O mantra é repetido e as possibilidades de reversão do fogo estancadas.

Essa questão aparece no Circuito dos Afetos quando Safatle abre o texto tratando da descoberta de Joseph $\mathrm{K}$ ao resolver voltar ao tribunal onde se desenrola seu processo, encontra a mulher do oficial de justiça. Ele the pede para ver os livros sobre a mesa. Ela nega e $\mathrm{K}$ considera ser essa negativa o principal motor da sujeição: a ignorância em relação aos meandros do poder. Ele vira o jogo quando depois de uma intimidade com a mulher, ela aceita mostrar os livros que nada tem de leis, tem apenas pornografias baratas. $\mathrm{K}$ comenta um pouco espantado sobre os homens que os julgam, mas Safatle questiona o que de fato K viu? Ele considera que o acusado deve ter visto a ausência de fundamentos e as arbitrariedades que anunciaria o inicio do século XX, com a consciência da crise de legitimidade do poder, ou a pornografia seria ela mesma, nesse tempo de gozo sem corporeidade, aquilo que a nossos olhos não podem ser indiferentes porque nos afeta, pela atração ou pela 
repulsa. No lugar das leis, das normas e das regras, apenas um circuito dos afetos.

Afetos que se deslocam do medo ao desamparo, pois tornou-se necessário pelo fogo contínuo partir-se da constatação de que os modos de gestão social do medo, sua produção e circulação são oriundas das estratégias de aquiescência à norma. Deste modo, produzir e mobilizar continuamente o medo da despossessão dos bens, da invasão da privacidade, do desrespeito à integridade etc., se torna motor da coesão social. Ele, como afeto político central é indissociável da compreensão do indivíduo com seus sistemas de interesses, suas fronteiras continuamente defendidas, fundamento dos processos de reconhecimento. Suas incorporações ou afecções orgânicas e não racionais, nos fazem agir de determinadas formas, pois cada regime de corporeidade tem seu modo de afecção. Epidemias, violências eminentes nas relações entre indivíduos, ou de outro modo, fazer com que a esperança seria o afeto capaz de se contrapor a esse corpo paranoico.

Mas não há poder que se funde exclusivamente no medo, e deste modo, ele não é só culpa e coerção ele também é esperança e gozo. Portanto, viver sem esperança é também viver sem medo. Mas, como o corpo esse medo tem seu regime, ele se defronta com a expectativa. Um tempo da espera que nos retira da potencialidade própria do instante. Vivenciando a crença esperançosa no porvir ou amedrontado por uma providencia perdida ou nunca alcançada.

Esse dilema foi refletido por Claude Lefort ao tentar descorporificar o social como forma de pretensamente garantir a invenção democrática, pela abertura de um espaço simbolicamente vazio no centro do poder. Ou seja esfriar o entusiasmo e calar o medo. Mas, afirma Safatle: é impossível descorporificar o social, pois é impossível purificar o espaço político de todo o afeto.(2016:p21). O desamparo cria vínculos tanto pela demanda de amparo ao outro, como vínculos de despossessão (Judith Butler) por absorção de contingências, ou seja, abre-me a um afeto que me despossui dos predicados que me identificam.

Assim, o corpo político produzido pelo desamparo está em contínua despossessão e des-identificação de suas determinações. Corpo sem eu comum e unicidade, atravessado por antagonismos e marcado por contingências que o desorganizam (normatividades, impulsionando as formas rumo a situações impredicadas. (2016. p22-22). Pelas consequências dessa situação chega-se ao âmago da destituição da ficção da pessoa individualizada. Assim, aparece para ele no circuito dos afetos a quarta linha de força que consiste em compreender a partir de uma certa tradição dialética, as condições para a emergência de sujeitos políticos, sem institucionalidades e rumo a ordenação social de diferenças.

Em Cinismo e falência da crítica, Safatle questionou a exigência de processos disciplinares de conformação e padrões normativos assim definidos. Nesse horizonte funda-se uma política que recusa, ao mesmo tempo, a crença na força transformadora tanto da identidade, quanto do reconhecimento das diferenças. Ambas são complementares. Elas são dois momentos do mesmo processo. Os sujeitos despossuídos de suas determinações, tornam-se desamparados.

Uma biopolítica de intervenção diferente daquela baseada nas formas disciplinares e da coerção normativa, mas da internalização da experiência da anomia produzida pela universalização da forma geral da intercambiabilidade e da equivalência. Mas, ele mesmo pondera que não é possível pensar a existência de uma sociedade desprovida da violência. Há uma violência produzida pela vida pulsional que se manifesta através da abertura à contingência, à indeterminação e à despossessão. Nem todas as violências equivalem-se em sua destrutividade, diz Vladmir. Ele sugere a necessidade de reler os textos que trataram dessa ambiguidade em busca de uma compreensão mais adequada do conceito em suas formas e realidades. ( Marx, Foucault, Deleuze, Lyotard).

Mas, ele também procura ver se há possibilidade de articulação entre política e biologia e, para isso, con- 
sidera que alguns autores realizaram uma operação astuta seguindo Georges Bataille, Canguilhem e Simondon que deram voltagem especulativa renovada ao conceito de vida. Caminho aberto por Georges Canguilhem que perguntou se sabemos exatamente o que dizer quando aproximamos a sociedade de um organismo, de um corpo orgânico? Uma guinada naturalista da crítica social, fruto da crítica a uma certa metafísica, pois herdamos do pensamento moderno a dicotomia na crença de uma distinção estrita entre liberdade (ação )e natureza (coisa). Melhor caminho para ele, é se apoiar em reflexões sobre a natureza do corpo vivente.

Em Grande Hotel Abismo, lançou as bases para uma ontologia subtrativa do sujeito e suas consequências para a reflexão sobre o processo de reconhecimento. Ontologia como pressão subtrativa do que não se esgota na configuração da situação atual dos entes ou do que não se esgota nas determinações gerais da atualidade. Critica das formas atuais e a apresentação de formas gerais de movimento que desarticulam o campo das identidades. Isto porque o sujeito não é uma entidade substancial dotada de unidade, identidade e autonomia. Ele não é um individuo ou uma pessoa, não tem a forma de um Eu. Ele é espaço de uma experiência de descentramento (Lacan) e não-identidade (Adorno). Na Segunda Meditação, como fez Descartes depois, de enunciar o cogito: que sou, eu que sei que sou?

Safatle nos diz que nesse livro muitas questões foram formuladas e problemas ainda estão em aberto, sendo o Circuito dos Afetos um retorno inicial aos problemas levantados no tratamento da dialética.(p.30). 0 problema também é de ordem psicológica, ou seja, o que leva os indivíduos que nos tornamos a se implicarem como sujeitos? Ao me implicar com algo qual afeto me implica tal processo? Qual afeto nos abre para sermos sujeitos?

Para criar sujeitos é necessário inicialmente desamparar-se.(p.31). É necessário mover-se para fora do que nos promete amparo, sair fora da ordem que nos individualiza, que nos predica no interior da situação atual. Há uma compreensão da inevitabilidade do impossível, do colapso do nosso sistema de possíveis que faz um individuo um sujeito. $O$ desamparo não é apenas demanda de amparo e cuidado. Melhor chamar de cuidado pelo Outro, de frustração. Mas também conforme Derrida, de uma heteronomia sem sujeição. Uma liberdade na não sujeição ao outro. (p.31 fim). Assim, sou a causa de minha própria transformação ao me implicar com algo que, ao mesmo tempo, me é heterônimo, mas me é interno sem me ser exatamente próprio. Uma heteronomia sem servidão. O que também não poderia ser diferente, já que amar alguém é amar suas linhas de fuga.

Saltar no vazio talvez seja, o único gesto necessário atualmente diz Safatle, pois o vazio pensado como o lugar no qual não encontramos nada foi considerado grande engano daqueles que conceberam um nada determinado. A arte e mesmo Hegel demonstraram que o silêncio é apenas uma abstração conceitual inefetiva, o vazio é o lugar onde não encontramos nada determinado, invisível por aqueles que se deixam afetar apenas de forma paralítica. (p.35)

Safatle entretanto, prefere compreender a forma como indivíduos produzem crenças, desejos e interesses a partir de certos circuitos de afetos ao justificarem a si mesmos, a necessidade de aquiescer à norma adotando alguns comportamentos e recusando outros. (p.38) Ele alerta que Freud também quer compreender como os afetos são produzidos e mobilizados para bloquear o que normalmente chamaríamos de "expectativas emancipatórias".

Deste modo, esse nosso encontro numa aula inaugural na Universidade de Taubaté se instituiu a partir de um circuito de afetos que reuniu Suzana e Raquel, duas queridas alunas, hoje docentes desta casa, a me instigar para um encontro onde se colocam para cada um de nós, expectativas de comunicação e desafios em tempo de dissolução de valores. Éticos, morais, de cidadania, de responsabilidades sociais e de reconhecimento da crise que se abateu em nossos circuitos de afetos.

O que nos implica hoje é saber que a capacidade instauradora de afecções tem consequências políticas maiores. Pois tanto a superação dos conflitos psíquicos quanto a possibilidade de experiências políticas de 
emancipação supõem a mutação dos afetos, ou seja, de sermos afetados de outra forma. Assim, pergunto a vocês quais são as suas condições psíquicas para a emancipação social e sobre a natureza sensível de seus bloqueios?

Como nos afetarmos sobre os desmandos políticos, sobre as desigualdades, sobre as violências cotidianas que estão visíveis e nos mantém tolerantes, alienados, alheios?

Se nossa capacidade de afecção está centrada na relação com as lideranças, esse é o verdadeiro ponto obscuro da reflexão política contemporânea. Assim, há proeminência do poder soberano na sociedade contemporânea, mesmo que seja de forma fantasmática e isso supõe que as verticalidades e hierarquias ainda são estruturas presentes e muito poderosas impedindo que a democracia supere os circuitos de afetos que sobrepõem autoridades a indivíduos, formas autocráticas a afetos que de articulem por equivalências e igualdades. Isto indica fenômenos de regressão, de indivíduos inaptos à maturidade democrática.

Está é a principal questão que nesta aula poderia trazer à consideração de todos, pois a vida Universitária tem como atividade precípua superar os entraves existentes ao exercício da liberdade, da autonomia e da responsabilidade de cada um na esfera de atuação que escolheu nesse lugar que só tem significado e importância se for um preparador da vida nua, da liberdade exponencial onde conhecimento e crítica são díades inseparáveis.

Mas, vejamos as distâncias existentes entre os rituais, as palavras e o significado das tarefas necessárias ao projeto futuro: o Reitor é qualificado de magnífico; as excelências são pessoas e não descobertas, soluções, superações; as igualdades são sinais entre os mesmos eliminando as diferenças; o diálogo é com os países centrais e o reconhecimento no exterior.

Além disso, ingressam nas instituições de ensino os que tem renda e os que conseguiram frequentar as escolas dos primeiros estudos que contam com infraestrutura adequadas, tem corpo docente concursado e bem formado, possui bibliotecas, laboratórios e acervos culturais que colocaram em debate ao longo de todo o processo inicial de formação.

Deste modo, ao longo de toda a infância e adolescência houve circuito de afetos capazes de fazer com que os estudantes recebesses o que o Estado promete e em geral, não cumpre. Essas ausências criam estigmas e definem meritocracia onde o que existe é acesso e direitos respeitados. Os que foram excluídos são considerados incapazes, alienados, preguiçosos, responsáveis por sua situação social e cultural e, deste modo, sem direitos por não ter se esforçado quando necessário.

Evidentemente, essa fantasia supõem a necessidade de um pai primevo capaz de salvar os que se destacam e dar a eles as referências e chancelas do sucesso, os aplausos e as distinções que reafirmam o soberano e a necessidade de um cinturão sanitário separando "o joio do trigo".

Ao invés de toda essa sacralização do poder, o que devemos marcar nessa cerimônia é a certeza de que estamos aqui por um imenso acaso que nos tirou da massa dos excluídos ou devido as desigualdades inerentes a estrutura de um país rentista num sistema de capitalismo e barbárie resultado das imposturas de um país que a cada três ou quatro décadas golpeia a frágil e intermitente democracia de baixíssima intensidade que exclui majoritariamente os despossuídos fazendo-os acreditar que são incompetentes e responsáveis por viverem sem direitos.

Essa é a consciência necessária que cada um de nós deve portar ao ingressar numa instituição Universitária e lutar sem tréguas para reverter essa história.

Obrigada. 